\title{
The effect of composition on the bond structure and refractive index of silicon nitride deposited by HWCVD and PECVD
}

\author{
V. Verlaan ${ }^{\text {a }}$, A.D. Verkerk ${ }^{\text {a }}$, W.M. Arnoldbik ${ }^{\text {a }}$, C.H.M. van der Werf ${ }^{\text {a }}$, R. Bakker ${ }^{\text {a }}$, Z.S. Houweling ${ }^{\text {, }}$, \\ I.G. Romijn ${ }^{\text {b }}$, D.M. Borsa ${ }^{\text {b }}$, A.W. Weeber ${ }^{\text {b }}$, S.L. Luxembourg ${ }^{c}$, M. Zeman ${ }^{\text {c }}$, H.F.W. Dekkers ${ }^{\text {d }}$, R.E.I. Schropp ${ }^{\text {a,* }}$ \\ ${ }^{a}$ Utrecht University, Faculty of Science, Debye Institute for Nanomaterials Science, Nanophotonics - Physics of Devices, P.O. Box 80.000, 3508 TA Utrecht, The Netherlands \\ ${ }^{b}$ ECN Solar Energy, Petten, The Netherlands \\ c DIMES, Delft University of Technology, The Netherlands \\ ${ }^{\mathrm{d}}$ IMEC, Leuven, Belgium
}

\section{A R T I C L E I N F O}

Available online 27 January 2009

Keywords:

Hot Wire CVD

Silicon nitride

\begin{abstract}
A B S T R A C T
Silicon nitride $\left(\mathrm{SiN}_{x}\right)$ is a material with many applications and can be deposited with various deposition techniques. Series of $\mathrm{SiN}_{x}$ films were deposited with HWCVD, RF PECVD, MW PECVD and LF PECVD. The atomic densities are quantified using RBS and ERD. The influence of the atomic densities on the Si-N and Si-Si bond structure is studied. The density of $\mathrm{N}-\mathrm{N}$ bonds is found to be negligible. New Si-N FTIR proportionality factors are determined which increase with increasing $\mathrm{N} / \mathrm{Si}$ ratio from $1.2 \cdot 10^{19} \mathrm{~cm}^{-1}$ for $\mathrm{Si}$ rich films $(\mathrm{N} / \mathrm{Si}=0.2)$ to $2.4 \cdot 10^{19} \mathrm{~cm}^{-1}$ for $\mathrm{N}$ rich films $(\mathrm{N} / \mathrm{Si}=1.5)$. The peak position of the $\mathrm{Si}-\mathrm{H}$ stretching mode in the FTIR spectrum is discussed using the chemical induction model. It is shown that especially for Si-rich films the hydrogen content affects the $\mathrm{Si}-\mathrm{H}$ peak position. The influence of the composition on the refractive index of the films is discussed on the basis of the Lorentz-Lorenz equation and the Kramers-Kronig relation. The decreasing refractive index with increasing $\mathrm{N} / \mathrm{Si}$ ratio is primarily caused by an increase of the band gap.
\end{abstract}

(c) 2009 Elsevier B.V. All rights reserved.

\section{Introduction}

Silicon nitride $\left(\mathrm{SiN}_{x}\right)$ has many applications and can be deposited using various chemical vapor deposition (CVD) techniques. To optimize the films for different applications, knowledge about the influence of the composition on the bonding structure and refractive index is necessary. To obtain this insight, the correlation between composition, bond structure and refractive index of $\mathrm{SiN}_{x}$ films deposited using different techniques is compared. By comparing these films, fundamental relations between the properties are obtained.

\section{Experimental details}

$\mathrm{SiN}_{x}$ films were deposited using Hot Wire (HW) CVD [1], radio frequency (RF) plasma enhanced (PE) CVD [2], pulsed low frequency (LF) PECVD [3] and microwave (MW) PECVD [4]. The composition of the films was varied by adjusting the silane to ammonia flow ratio, except for the LF PECVD films where only the substrate temperature was altered. The substrate temperatures during deposition were

\footnotetext{
* Corresponding author.

E-mail address: r.e.i.schropp@uu.nl (R.E.I. Schropp).
}

$450{ }^{\circ} \mathrm{C}$ for the HWCVD, $350{ }^{\circ} \mathrm{C}$ for MW PECVD, $235{ }^{\circ} \mathrm{C}$ for RF PECVD and between 200 and $500{ }^{\circ} \mathrm{C}$ for LF PECVD.

All films were subsequently analyzed with Fourier transform infrared spectroscopy (FTIR), Rutherford backscattering (RBS) and elastic recoil detection (ERD). The FTIR spectra were obtained under $\mathrm{N}_{2}$ purging and afterwards corrected for coherent and incoherent reflections [5]. For an accurate determination of the ratio between the $\mathrm{Si}, \mathrm{N}$ and $\mathrm{H}$ atoms, ERD [6] was applied employing a $50 \mathrm{MeV} \mathrm{Cu}^{8+}$ ion beam. Here a gas filled ionization chamber was used for background free detection for the separate elements. $2 \mathrm{MeV} \mathrm{He}^{+}$ions were used for the RBS [7] measurements. The areal densities were determined by simulation of the RBS spectra with the ERD results as input for the RUMP simulation package [8]. The refractive indices and thicknesses were determined with either ellipsometry or reflection/transmission measurements.

\section{Compositional properties}

Fig. 1 shows the $\mathrm{H}, \mathrm{N}$ and $\mathrm{Si}$ volume densities (in $\mathrm{at} / \mathrm{cm}^{3}$ ) as a function of the N/Si ratio. HWCVD and MW PECVD show similar trends. It is of interest that the Si density for HWCVD and MW PECVD films is almost invariable. For N rich (N/Si $>1.3)$ HWCVD films both the $\mathrm{N}$ and $\mathrm{Si}$ densities decrease. The $\mathrm{H}$ density is roughly constant for HWCVD and MW PECVD films with N/Si ratios larger than 0.5 and 


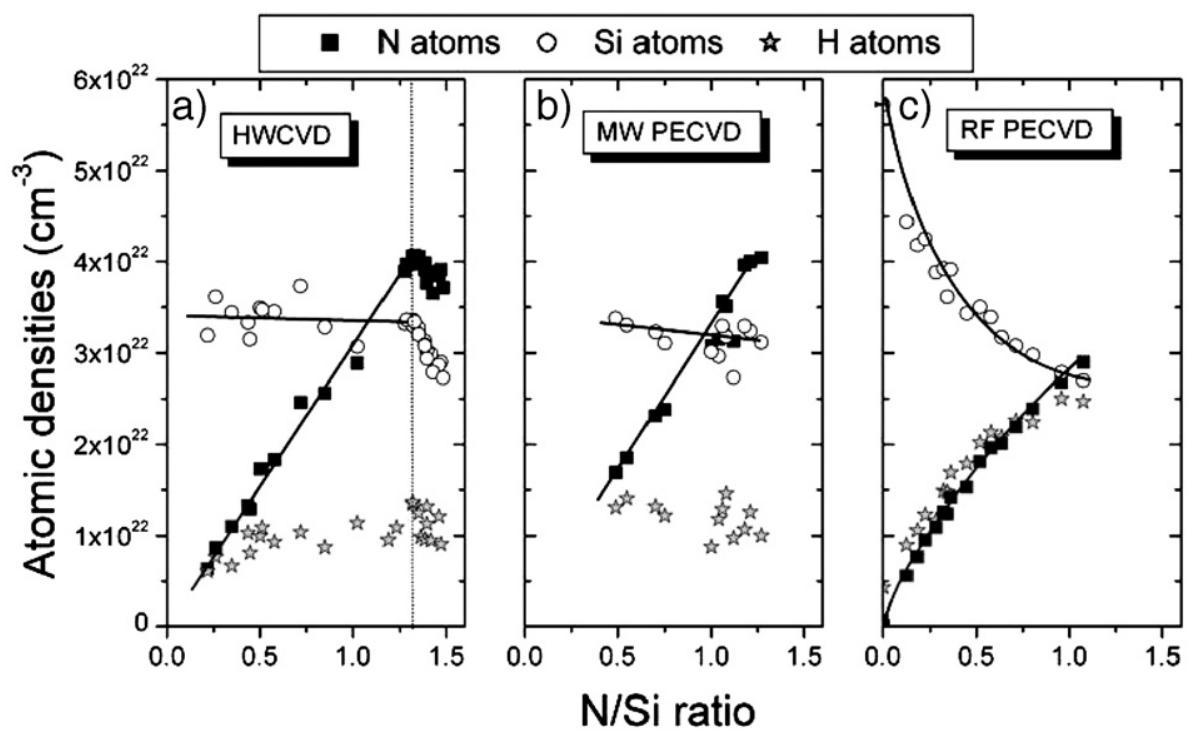

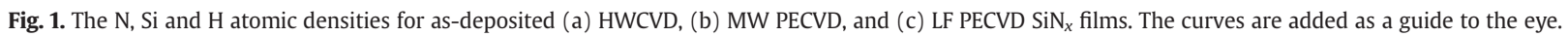

amounts to about $1 \cdot 10^{22}$ at $/ \mathrm{cm}^{3}$. The densities of the RF PECVD films show different trends; both the $\mathrm{N}$ and $\mathrm{H}$ densities increase for increasing $\mathrm{N} / \mathrm{Si}$ ratios and the $\mathrm{Si}$ density decreases. These trends are possibly influenced by the deposition parameters and therefore they are not necessarily typical for the deposition technique used. The wide range of obtained compositions provides fundamental insight in the correlations between the composition, the bond structure and the refractive index.

\section{4. $\mathrm{Si}-\mathrm{N}$ and $\mathrm{Si}-\mathrm{Si}$ bond structure}

A frequently used technique to study the bond structure is FTIR. The largest peak in the FTIR spectra is found around $840 \mathrm{~cm}^{-1}$, which is dominated by the $\mathrm{Si}-\mathrm{N}$ stretching mode. A maximum for the integrated absorption [9] of the $\mathrm{Si}-\mathrm{N}$ peak $\left(I_{\mathrm{Si}-\mathrm{N}}\right)$ is reached at the $\mathrm{N} / \mathrm{Si}$ ratio where the $\mathrm{N}$ density peaks $(\mathrm{N} / \mathrm{Si}=4 / 3)$.
The Si-Si and N-N bond densities are estimated by combining ERD, RBS and FTIR analysis. Eqs. (1) and (2) hold, under the assumption that the amounts of $\mathrm{N}$ and Si dangling bonds are negligible.

$$
\begin{aligned}
& 3 \mathrm{~N}_{\mathrm{N}}=[\mathrm{Si}-\mathrm{N}]+[\mathrm{N}-\mathrm{H}]+2[\mathrm{~N}-\mathrm{N}] \\
& 4 \mathrm{~N}_{\mathrm{Si}}=[\mathrm{Si}-\mathrm{N}]+[\mathrm{Si}-\mathrm{H}]+2[\mathrm{Si}-\mathrm{Si}]
\end{aligned}
$$

where $\mathrm{N}_{\mathrm{N}}$ and $\mathrm{N}_{\mathrm{Si}}$ are the atom densities and $[X-Y]$ the density of bonds between atoms $X$ and $Y$. The asymmetric bond densities are obtained from FTIR analysis, using the FTIR proportionality factors from Lanford and Rand [10] for N-H and Si-H and Bustarret et al. [11] for Si-N. The determined N-N and Si-Si densities are shown in Fig. 2 (a). Both bond densities show a similar trend for all samples. The density of $\mathrm{Si}-\mathrm{Si}$ bonds is zero for $\mathrm{N}$-rich films and increases with decreasing $\mathrm{N} / \mathrm{Si}$ ratio. The density of $\mathrm{N}-\mathrm{N}$ bond is negligible for all compositions. A Raman measurement of a HWCVD $\mathrm{SiN}_{0.9}$ film

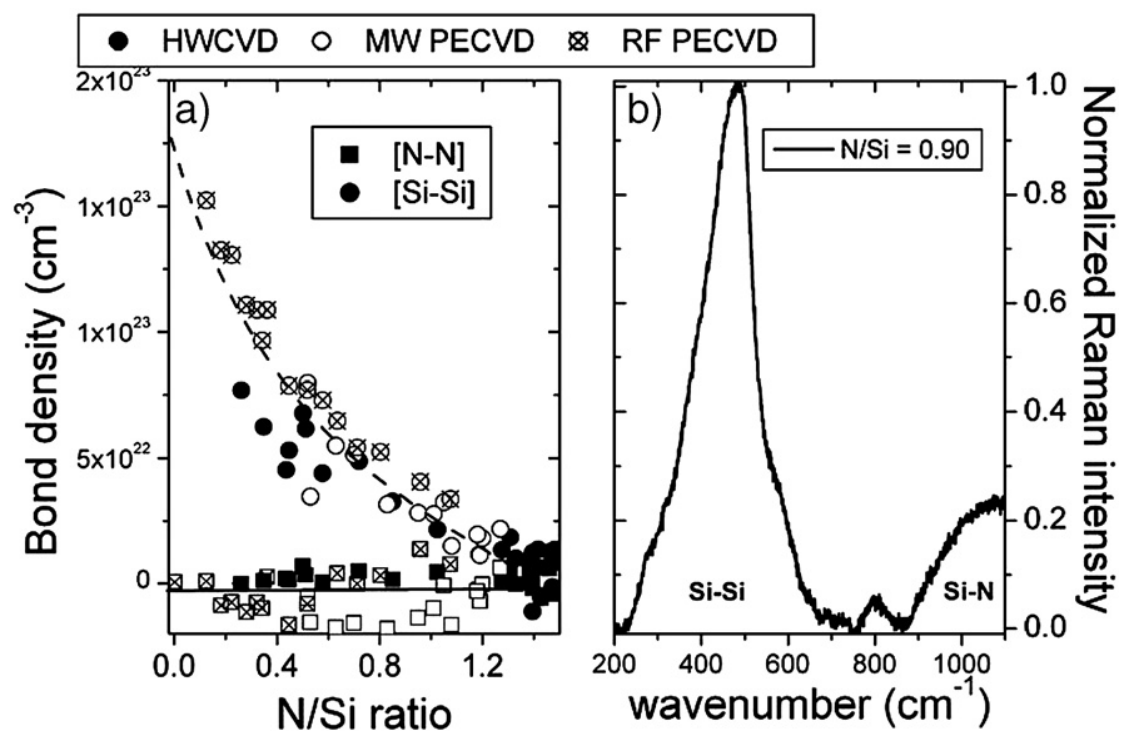

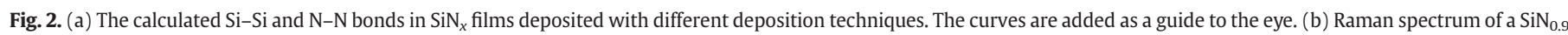
film. The Si-Si contribution is clearly visible. 


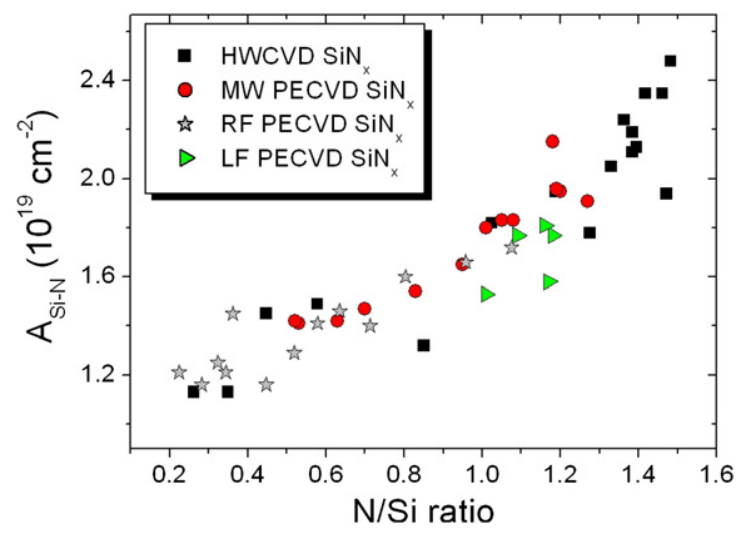

Fig. 3. The Si-N proportionality factor for films deposited with different techniques versus the $\mathrm{N} / \mathrm{Si}$ ratio.

(Fig. 2(b)) confirms the presence of Si-Si bonds by the band that is present at $480 \mathrm{~cm}^{-1}$.

Since the amount of $\mathrm{N}-\mathrm{N}$ is negligible and the density of $\mathrm{Si}-\mathrm{N}$ bonds can be calculated by multiplying $I_{S i-N}$ with the FTIR proportionality factor $A_{S i-N}, A_{S i-N}$ can be determined by rewriting Eq. (1) to:

$A_{S i-N}=\frac{3 N_{N}-[N-\mathrm{H}]}{I_{S i-N}}$.

This induces an error since the $\mathrm{N}-\mathrm{H}$ proportionality factor changes with composition [12]. However, since $N_{N} \gg[\mathrm{N}-\mathrm{H}]$ the error caused by incorrect $[\mathrm{N}-\mathrm{H}]$ in $A_{S i-N}$ is limited to less than $2 \%$. Fig. 3 shows $A_{S i-N}$ for films in a wide range of $\mathrm{N} / \mathrm{Si}$ ratios. A general increasing trend is present for all deposition techniques used. For Si-rich films the $A_{S i-N}$ is $1.2 \cdot 10^{19} \mathrm{~cm}^{-2}$. The value increases with increasing $\mathrm{N} / \mathrm{Si}$ ratio to $2.4 \cdot 10^{19} \mathrm{~cm}^{-2}$ for N-rich films. A similar trend has been reported earlier, although they reported slightly smaller values between $0.8 \cdot 10^{19}$ and $2.0 \cdot 10^{19} \mathrm{~cm}^{-2}[11]$.

\section{The position of the FTIR Si-H stretching mode}

Fig. 4 shows the $\mathrm{Si}-\mathrm{H}$ peak position for the present $\mathrm{SiN}_{x}$ films along with data found in literature [13-17]. For films with an N/Si ratio larger than 0.6 , the $\mathrm{Si}-\mathrm{H}$ peak positions are similar, for films with an $\mathrm{N} / \mathrm{Si}$ ratio smaller than 0.6 discrepancies appear. These differences can be as large as $50 \mathrm{~cm}^{-1}$ for films with equal N/Si ratio. To obtain insight in the $\mathrm{Si}-\mathrm{H}$ peak position in Si alloys, the chemical induction method [18-20] is applied. This model accounts for differences in the effective electronegativity sum that forms the local environment of the $\mathrm{Si}-\mathrm{H}$ bonds and thus accounts for differences in primary, secondary and higher orders of back bonding. The $\mathrm{Si}-\mathrm{H}$ peak position as a result of the back bonding configuration is described by:

$\omega\left(\mathrm{cm}^{-1}\right)=1630+49 \sum_{j=1}^{3} \chi_{\mathrm{A}_{\mathrm{j}}}$

where $\chi_{A j}$ is the effective electronegativity of the $j^{\text {th }}$ neighbor of the $\mathrm{Si}-\mathrm{H}$ bond. The $\chi_{A j}$ for each type of neighboring atom is determined as the geometric average by;

$\chi_{A_{J}}=\left[\chi_{j} \chi_{\mathrm{m}}^{k}\right]^{\frac{1}{(1+k)}}$

where $\chi_{j}$ is the stability ratio of the electronegativity of each element $\left(\chi_{\mathrm{Si}}=2.62, \chi_{\mathrm{N}}=4.49\right.$ and $\left.\chi_{\mathrm{H}}=3.55[18]\right)$ and $k$ is the number of second nearest sites ( 2 for $\mathrm{N}$ and 3 for $\mathrm{Si}$ ). $\chi_{\mathrm{m}}$ is the average electronegativity and thus accounts for the matrix effects. $\chi_{\mathrm{m}}$ can consequently be determined using:

$\chi_{\mathrm{m}}=\left[\chi_{\mathrm{Si}} \chi_{\mathrm{N}}^{r} \chi_{\mathrm{H}}^{q}\right]^{\frac{1}{(1+r+q)}}$

where $r$ is the $\mathrm{N} / \mathrm{Si}$ ratio and $q$ the $\mathrm{H} / \mathrm{Si}$ ratio. Since $\chi_{\mathrm{m}}$ changes by differences in $\mathrm{N} / \mathrm{Si}$ and $\mathrm{H} / \mathrm{Si}$ ratio, the $\mathrm{Si}-\mathrm{H}$ peak position depends not only on the primary back bonding but also on the hydrogen content [20]. Because the hydrogen concentration can reach values as high as 30 at.\%, this model should also account for $-\mathrm{Si}-\mathrm{H}_{2}$ and $-\mathrm{Si}-\mathrm{H}_{3}$ groups since they are likely to be present. This extends the model as reported so far. Each of the three back bonding possibilities for the Si host atoms is thus described by;

$$
\begin{aligned}
& \chi_{A}^{S i}=\left[\chi_{S i} \chi_{\mathrm{m}}^{3}\right]^{1 / 4} \\
& \chi_{A}^{N}=\left[\chi_{N} \chi_{\mathrm{m}}^{2}\right]^{1 / 3} \\
& \chi_{A}^{H}=\left[\chi_{H}\right]
\end{aligned}
$$

Eq. (6) shows that the $\mathrm{Si}-\mathrm{H}$ peak position of each back bonding configuration is affected by the $\mathrm{N} / \mathrm{Si}$ and $\mathrm{H} / \mathrm{Si}$ ratios. The influence of the $\mathrm{H} / \mathrm{Si}$ ratio in the layer is very small for near stoichiometric films, but it causes significant peak shifts for Si-rich films [20].

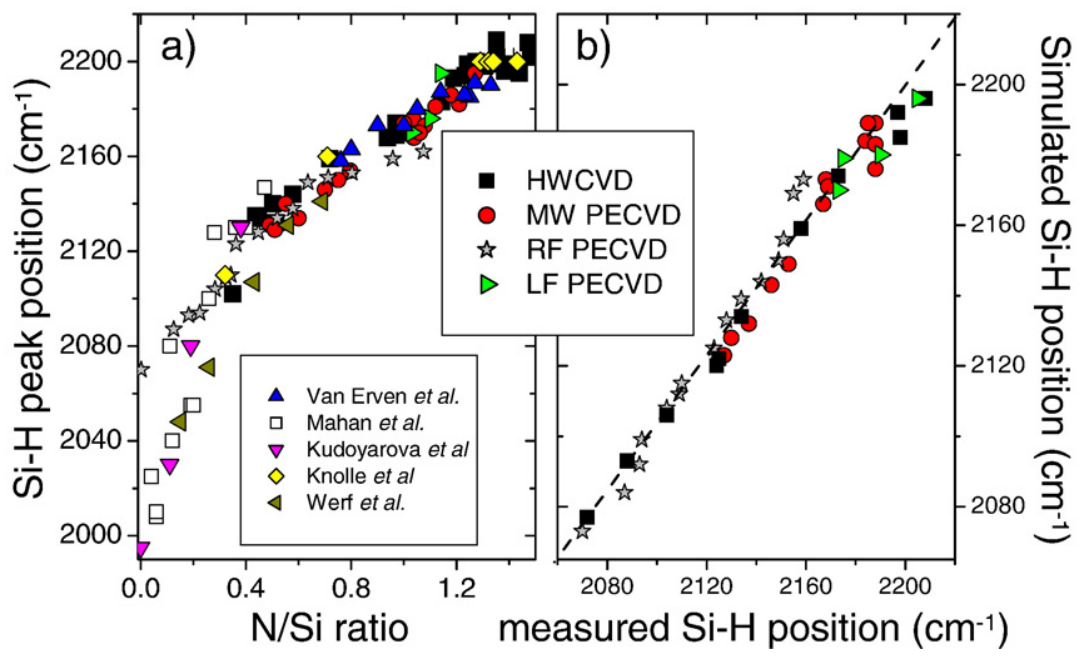

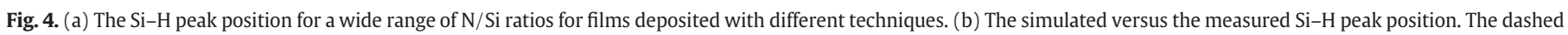
line represents prefect agreement between the two. 


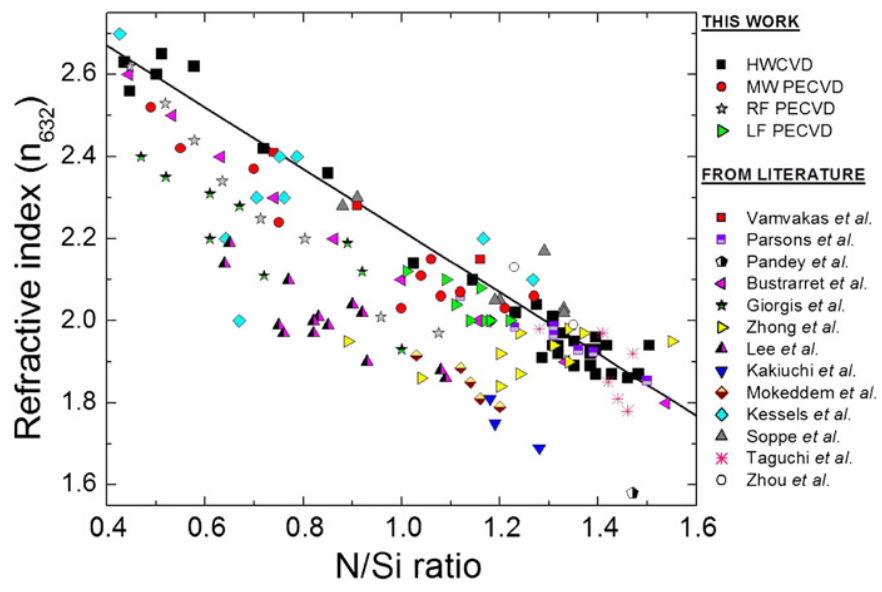

Fig. 5. Correlation between the refractive index at $632 \mathrm{~nm}$ and the N/Si ratio for $\mathrm{SiN}_{x}$ films deposited with different deposition techniques. The black line is a linear fit through the data of the HWCVD films.

To simulate the peak position of the $\mathrm{Si}-\mathrm{H}$ stretching mode in the FTIR spectrum, the positions of all possible bond configurations are determined (using Eq. (4)) and scaled in intensity with their respective probabilities of occurrence. To determine these probabilities, a random bonding configuration and homogeneous atom distribution are assumed. By adding Gaussian shaped contributions (with a width of $90 \mathrm{~cm}^{-1}$ ) for each back bonding configuration in proportion to their probability of occurrence of each back bonding configuration, the position of the combined $\mathrm{Si}-\mathrm{H}$ stretching mode is simulated $[18,19]$. Fig. $4 \mathrm{~b}$ shows the data for the simulated versus the measured peak positions. The close correlation shows that this model is appropriate and thus the influence of the hydrogen concentration on the position of the $\mathrm{Si}-\mathrm{H}$ stretching mode peak.

\section{Refractive index}

Fig. 5 shows the refractive index at $632 \mathrm{~nm}, n_{632}$, of the present films versus the $\mathrm{N} / \mathrm{Si}$ ratio, combined with data from literature [11,2129]. The understanding of the influence of the composition on the refractive index can be improved by using the Lorentz-Lorenz formula. This equation relates the total polarizability of a specific medium consisting of perfect spheres to its refractive index by

$\frac{n^{2}-1}{n^{2}+2}=\frac{4 \pi}{3} \sum_{k} N_{k} \alpha_{k}$

in which $n$ is the refractive index, $\alpha_{k}$ is the electronic polarizability and $N_{k}$ is the atomic density of atom $k$. Eq. (10) shows that films with equal $\mathrm{N} / \mathrm{Si}$ ratio but smaller mass density have smaller values for $n_{632}$. So the dissimilarity in $n_{632}$ for films with equal $\mathrm{N} / \mathrm{Si}$ ratio might be caused by differences in mass density. Consequently, the refractive index alone is not a suitable way to determine the $\mathrm{N} / \mathrm{Si}$ ratio in $\mathrm{SiN}_{x}$ films.

Since the Lorentz-Lorenz equation predicts an increase of $n_{632}$ when more $\mathrm{N}$ atoms are incorporated (as is the case for the HWCVD and MW PECVD $\mathrm{SiN}_{x}$ films), these equation fails to explain the observed negative trend with increasing $\mathrm{N} / \mathrm{Si}$ ratio.

The correct explanation for the wide spread in refractive index may be found in the increase of the band gap energy with increasing $\mathrm{N} / \mathrm{Si}$ ratio. According to the Kramers-Kronig dispersion relation the refractive index is affected by the blue shift of the absorption. If the refractive index is probed in a region of strong dispersion, the blue shift consequently causes a decrease of $n$. Since the band gap is the largest for the N-rich films, the refractive index is lowest for these samples. To confirm this hypothesis numerical simulations of the Kramers-Kronig relation are performed and show good agreement with the experimental data [30].

\section{Conclusions}

The atomic volume densities of HWCVD, RF PECVD, MW PECVD and LF PECVD silicon nitride samples are quantified using ERD and RBS. For HWCVD and MW PECVD the Si and H volume density is equal for all compositions. These atomic densities are used to determine their influence on the $\mathrm{Si}-\mathrm{N}, \mathrm{N}-\mathrm{N}$ and $\mathrm{Si}-\mathrm{Si}$ bond structure. The amount of $\mathrm{N}-\mathrm{N}$ bonds is found to be negligible for all samples, and the amount of $\mathrm{Si}-\mathrm{Si}$ bonds decreases with increasing N/Si ratio.

New Si-N FTIR proportionality factors were calculated, which increase with increasing $\mathrm{N} / \mathrm{Si}$ ratio from $1.2 \cdot 10^{19} \mathrm{~cm}^{-1}$ for Si-rich films $(\mathrm{N} / \mathrm{Si}=0.2)$ to $2.4 \cdot 10^{19} \mathrm{~cm}^{-1}$ for $\mathrm{N}$ rich films $(\mathrm{N} / \mathrm{Si}=1.5)$. The peak position of the $\mathrm{Si}-\mathrm{H}$ stretching mode in the FTIR spectrum is discussed using the chemical induction model. This shows that the N/Si ratio is not solely dependent on the $\mathrm{N} / \mathrm{Si}$ ratio but also on the hydrogen concentration. The influence of the composition on the refractive index of the films is discussed with the Lorentz-Lorenz equation and the Kramers-Kronig relation. No general correlation between the N/Si ratio and the refractive index is present. The LorenzLorentz equation fails to describe the influence of the composition on the refractive index. The decreasing refractive index with increasing $\mathrm{N} / \mathrm{Si}$ ratio is likely to be caused by an increase of the band gap.

\section{Acknowledgement}

Dr. E.E.H. van Faassen is acknowledged for fruitful discussions.

\section{References}

[1] V. Verlaan, Z.S. Houweling, C.H.M. Van der Werf, I.G. Romijn, A.W. Weeber, H.D. Goldbach, R.E.I. Schropp, Thin Solid Films 516 (2008) 533.

[2] S.L. Luxembourg, F.D. Tichelaar, P. Kus, M. Zeman, Mater. Res. Soc. Proc. 1066 (2008) A07-04.

[3] H.F.W. Dekkers, S. de Wolf, G. Agostinelli, F. Duerinckx, G. Beaucarne, Sol. Energy Mater. Sol. Cells 90 (2006) 3244.

[4] I.G. Romijn, W.J. Soppe, H.C. Rieffe, W.C. Sinke, and A.W. Weeber. Proc. 15th workshop on Crystal. Si solar cells and modules.

[5] N. Maley, Phys. Rev., B 46 (1992) 2078.

[6] W.M. Arnold Bik, F.H.P.M. Habraken, Rep. Prog. Phys. 56 (1993) 2530.

[7] W.K. Chu, J.W. Mayer, M.A. Nicolet, Backscattering Spectroscopy, Academic Press, NY, 1978.

[8] L.R. Doolittle, Nucl. Instrum. Methods B9 (1985) 344.

[9] M. Cardona, Phys. Status Solidi B 118 (1983) 463.

[10] W.A. Lanford, M.J. Rand, J. Appl. Phys. 49 (1978) 2473.

[11] E. Bustarret, M. Bensouda, M. Habrard, J. Breyere, S. Poulin, S. Gujrathi, Phys. Rev., B 38 (1998) 8171.

[12] V. Verlaan, C.H.M. van der Werf, W.M. Arnoldbik, H.D. Goldbach, R.E.I. Schropp Phys. Rev., B 73 (2006) 195333.

[13] A.J.M. van Erven, R. Bosch, O. Voigth, S. Petri, M.D. Blijker, Proc. Photovoltaic Solar Energy Conference, 2004.

[14] W.R. Knolle, J.S. Ossenbach, J. Appl. Phys. 58 (1985) 1248.

[15] V.K. Kudoyarova, A.A. Aivazov, B.G. Budaguan, I.V. Filatova, Mater. Res. Soc. Symp. Proc. 284 (1993) 127.

[16] A.H. Mahan, A.C. Dillon, I.M. Gedvillas, D.L. Williamson, J.D. Perrin, J. Appl. Phys. 94 (2003) 2360.

[17] C.H.M. van der Werf, H.D. Goldbach, J. Loffler, A. Scarfo, A. Kylner, B. Stannowski, W Arnoldbik, A. Weeber, H. Rieffe, W. Soppe, R.E.I. Schropp, Thin Solid Films 501 (2006) 51

[18] G. Lucovsky, Solid State Commun. 29 (1979) 517.

[19] G.N. Parsons, G. Lucovsky, Phys. Rev., B 41 (1990) 1664.

[20] A.A. Aivazov, B.G. Budaguan, D.A. Stryahiliv, J. Non-Cryst. Solids 167 (1994) 185.

[21] F. Giorgis, F. Giuliani, C. Pirri, E. Tresso, C. Summonte, R. Rizzoli, R. Galloni, A. Desalvo, P. Rava, Philos. Mag., B 77 (1998) 925.

[22] H. Kakiuchi, Y. Nakahama, H. Ohmi, K. Yasutake, K. Yoshi, Y. Mori, Thin Solid Films 479 (2005) 17.

[23] W.M.M. Kessels, J. Hong, F. Assche, J. Moschner, T. Lauinger, W.J. Soppe, A.W. Weeber, A. Schram, M.C.M. van der Sanden, J. Vac. Sci. Technol., A 20 (2002) 1704

[24] J. Lee, R. Ryoo, M.S. Jhon, K. Cho, J. Phys. Chem. Solids 56 (1995) 293.

[25] K. Mokeddem, M. Aoucher, T. Smail, Superlattices Microstruct. 40 (2006) 598.

[26] R.K. Pandey, L.S. Patil, J.P. Bange, D.K. Gautam, Opt. Mater. 27 (2004) 139.

[27] W.J. Soppe, J. Hong, W. Kessels, M. van der Sanden, W.M. Arnoldbik, C. Devilee, S. Schiermeier, A.W. Weeber, Proc. IEEE PVSEC (2002) 158.

[28] K. Taguchi, M. Yoshimoto, J. Saraie, A. Chayahara, Y. Horino, Jpn. J. Appl. Phys. 43 (2004) L1403.

[29] K. Zhu, K. Elgaid, C. Wolkinson, I. Thayne, Jpn. J. Appl. Phys. 45 (2006) 8388.

[30] V. Verlaan. Silicon nitride at high growth rate using hot wire chemical vapor deposition. PhD-thesis 2008. ISBN: 978-90-393-4882-6. 